\title{
PROPOSTA DE DESIGN PARA O MODELO DE NEGÓCIO DE UMA PLATAFORMA DIGITAL DE SERVIÇO
}

\author{
Alan Felismino da Silva \\ Universidade do Estado do Rio de Janeiro \\ bauerafs@gmail.com \\ André Ribeiro de Oliveira \\ Universidade do Estado do Rio de Janeiro \\ ribeiro74@gmail.com \\ Victor Hugo de Azevedo Meirelles \\ Wiiglo Tecnologia da Informação \\ victor@wiiglo.com
}

Resumo: O presente artigo aborda um caso real de design de um negócio baseado em uma plataforma tecnológica alavancadora de serviços digitais, desenvolvida por uma startup, incubada da Universidade do Estado do Rio de Janeiro. Através de uma síntese de conceitos e componentes presentes na literatura, foi organizado um quadro conceitual que busca atender os requisitos de modelos de negócios digitais. Tendo como base a síntese de modelos proposta por Orofino (2011), os elementos de cada modelo foram relacionados e organizados, servindo como arcabouço conceitual para o design do negócio baseado na plataforma de serviços digitais. Conclui-se ao final do estudo que tanto a síntese de conceitos de modelo de negócios digitais construída quanto o design do negócio da plataforma da startup atingem, respectivamente, o objetivo de encontrar novos elementos explorando os artifícios de diferenciação para um serviço digital e planejando uma estratégia aderente à realidade da organização.

Palavras-chave: modelos de negócio, design de negócios, plataformas digitais, serviços digitais.

Abstract: This article addresses a real case of a business design based on a technology platform of digital services developed by a startup incubated at the State University of Rio de Janeiro. Through a synthesis of concepts and components present in the literature, it was organized a conceptual framework that seeks to meet the requirements of digital business models. Based on the synthesis models proposed by Orofino (2011), the elements of each model were related and organized, serving as a conceptual framework for business design based on digital services platform. It was concluded at the end of the study that both the synthesis of digital business model concepts built as the startup digital platform business design reach, respectively, the goal of finding new elements exploring the differentiation 
of devices to a digital service and planning a cohesive strategy the reality of the organization.

Keywords: business model, business design, digital platforms, digital services.

\section{INTRODUÇÃO}

A inovação tem se mostrado um elemento primordial para sustentação da vantagem competitiva das organizações e das nações. Pesquisas realizadas, como a da Boston Consulting Group em 2006 (BCG, 2006), apontam que organizações consideradas inovadoras superam suas concorrentes não inovadoras em termos de market share e lucratividade no longo prazo. A inovação mostra-se, pois, uma importante fonte de vantagem competitiva das empresas já estabelecidas no mercado e, ao mesmo tempo, apresenta-se como elemento fundamental de sucesso das Micro e Pequenas Empresas de Base Tecnológica (MPEBT), em especial, aquelas comprometidas com o projeto, desenvolvimento e produção de novos produtos e/ou processos.

Tradicionalmente, essas empresas buscam reduzir as incertezas de suas iniciativas empreendedoras a partir da elaboração e implantação de planos de negócios conforma pode ser observado em Dolabela (1999), Berry (2006) e Sanguja (2014). Entretanto, autores como Teece (2010), Kalrsson e Honig (2009) e Baden-Fuller e Haefliger (2013) reconhecem algumas fragilidades críticas no uso desta abordagem, como a impossibilidade de se coletar dados históricos fidedignos, por ser um processo custoso e exigir constantes atualizações.

Complementar ao plano de negócios existe o Modelo de Negócio que, segundo Osterwalder (2004), utiliza premissas que podem ser mapeadas, testadas e, dinamicamente, implementadas a partir de resultados preliminares de tais testes. Quanto mais rápido se mapeia hipóteses de negócio, implementa premissas, testa e avalia possíveis reposicionamentos, mais chances de sucesso o empreendimento terá (RIES, 2012).

No contexto de uma MBEBT brasileira, encontra-se uma startup de Tecnologia da Informação foi fundada em 2013 e se encontra incubada na incubadora universitária de base tecnológica da Universidade do Estado do Rio de Janeiro. A startup desenvolveu uma plataforma tecnológica online própria baseada em sistemas georreferenciados ${ }^{1}$ e tratamento analítico de dados, para diversos fins.

1 O georreferenciamento de uma imagem ou um mapa ou qualquer outra forma de informação geográfica é tornar suas coordenadas conhecidas num dado sistema de referência. Este processo iniciase com a obtenção das coordenadas (pertencentes ao sistema no qual se pretende georreferenciar) de pontos da imagem ou do mapa a serem georreferenciados, conhecidos como pontos de controle. Os pontos de controle são locais que oferecem uma feição física perfeitamente identificável, tais como intersecções de estradas e de rios, represas, pistas de aeroportos, edifícios proeminentes, topos de montanha, entre outros. A obtenção das coordenadas dos pontos de controle pode ser realizada em campo (a partir de levantamentos topográficos, GPS - Sistema de Posicionamento Global), ou ainda por meio de mesas digitalizadoras, ou outras imagens ou mapas (em papel ou digitais) georreferenciado. (Fonte: http://pt.wikipedia.org/wiki/Georreferenciamento) 
Em um primeiro momento, não se sabia ao certo como deveria ser o modelo de negócios para a plataforma de maneira que fosse capaz de gerar receitas sustentáveis no mais longo prazo, gerando valor aos clientes e que, ao mesmo tempo, garantisse proteção contra concorrentes e imitadores. A elaboração de um plano de negócios levaria tempo considerável, não haveria informações históricas e os riscos e incertezas não seriam devidamente mensurados pela ausência de dados. A partir dessa situação decidiu-se então pela concepção de um modelo negócio que viabilizasse a comercialização de serviços a partir da utilização da plataforma, desenvolvida pela startup.

As particularidades do caso exigiram uma pesquisa acerca dos quadros conceituais presentes na literatura sobre modelos de negócios baseados em tecnologia e serviços digitais. Sob este aspecto, uma nova abordagem conceitual foi construída a partir da revisão da literatura, fortemente balizada por princípios de design, como a cocriação citada por exemplo por Plé, Lecocq \& Angot (2010) e Osterwalder \& Pigneur (2013).

O resultado do trabalho desenvolvido foi a apresentação de uma proposta metodológica para concepção de modelos de negócios voltados para a comercialização de serviços baseados em plataformas tecnológicas potenciais provedoras de serviços digitais, tendo como pano de fundo os princípios do design. A plataforma da startup foi utilizada como exemplo de aplicação dessa proposta.

O trabalho encontra-se organizado pelas seguintes seções: inicialmente são apresentadas as premissas e os quadros conceituais de modelos de negócio. Posteriormente é proposto um quadro conceitual derivado dos quadros conceituais identificados na literatura. Em seguida este quadro conceitual é aplicado com base nos princípios de design para conceber o modelo de negócios para a plataforma da startup e, ao final, tecemos as considerações finais sobre essa experiência.

\section{CONSTRUÇÃO DO QUADRO CONCEITUAL DE APOIO À ELABORAÇÃO DE MODELOS DE NEGÓCIOS BASEADOS EM PLATAFORMAS DIGITAIS}

Para Amit \& Zott (2010) o modelo de negócio pode ser definido como um conjunto de atividades específicas direcionadas a satisfazer as necessidades percebidas no mercado, junto com as especificações da empresa e dos parceiros que conduzem estas atividades, e como estas atividades estão relacionadas entre si. Osterwalder \& Pigneur (2013) definem o modelo de negócio como uma lógica de criação, entrega e captura de valor por parte de uma organização. A sua definição original vem da tese de doutorado do primeiro autor, como uma representação simplificada de como as empresas compram e vendem produtos e serviços e geram receitas (OSTERWALDER, 2004). Há inúmeras definições e diferentes propostas de modelos de negócios presentes na literatura. O modelo Canvas talvez seja o mais conhecido e utilizado atualmente, mas outros modelos, como os de Amit \& Zott (2001), Alt \& Zimmermann (2001), Pateli \& Giaglis (2003) e Chesbrough \& Rosenbloom (2002), foram propostos na literatura e também podem ser considerados para a utilização na startup.

A busca por tais modelos foi realizada nas bases de pesquisa online (CAPES, Google Academics, Scielo) utilizando a palavra-chave "business model", dentre outros repositórios como sites com artigos específicos e através das próprias referências 
bibliográficas de cada artigo. Como critério de seleção dos quadros conceituais, foram selecionados aqueles que explicitassem algumas premissas, a saber: (1) A inovação pela estratégia: Oferecer uma ideia forte de posicionamento de mercado e de inovação frente aos concorrentes; (2) A inovação pela rede de valor: Ligar requisitos técnicos e econômicos reduzindo a incertezas na rede de valor; (3) A inovação pelo cliente: Entender os clientes para expandir participação pelo entendimento de necessidades; (4) A inovação pela proposição de valor: Entender qual a melhor forma de apresentar e agregar valor ao produto/serviço.

A partir das premissas, chegou-se a um quadro sintético semelhante ao que foi apresentado por Orofino (2011). Esses quadros conceituais tiveram seus componentes identificados e decupados e assim foi possível organizar tais componentes que explicitam as premissas, como pode ser observado em Amit \& Zott (2001), Pateli \& Giaglis (2003), Chesbrough \& Rosenbloom (2002), Plé, Lecocq \& Angot (2010), Osterwalder \& Pigneur (2013). A tabela a seguir sintetiza os elementos presentes nesses quadros conceituais.

\begin{tabular}{|c|c|c|c|c|c|c|}
\hline \multirow[b]{2}{*}{ Componentes do Modelo de Negócio } & \multicolumn{6}{|c|}{ Autores } \\
\hline & Osterwalder & Plé et. al & Pateli et.al & Amit \& Zott & Chesbrogh et. al & Total \\
\hline Arquitetura de Valor & & & & & & 0 \\
\hline Aspectos financeiros & & & $\mathrm{x}$ & & & 1 \\
\hline Atividades e organização & $x$ & $x$ & & & & 2 \\
\hline Ativos & & & & & & 0 \\
\hline Captura de Valor & & & & & & 0 \\
\hline Cadeia de Valor & & & $\mathrm{x}$ & & $\mathrm{x}$ & 2 \\
\hline Competencias Organizacionais & & $\mathrm{x}$ & & & & 1 \\
\hline Concorrentes & & & $\mathrm{x}$ & & & 1 \\
\hline Conteúdo das Operações & & & & $\mathrm{x}$ & & 1 \\
\hline Criação de Valor & & $x$ & & & & 1 \\
\hline Estratégia Competitiva & & & $x$ & & $x$ & 2 \\
\hline Estrutura de Operações & & & & $x$ & & 1 \\
\hline Estrutura de Custos & $x$ & & $x$ & & $\mathrm{x}$ & 3 \\
\hline Estrutura de Tecnologia & & & & & & 0 \\
\hline Fator de Produção de Insumos & & & & & & 0 \\
\hline \begin{tabular}{|l|} 
Fatores Econômicos \\
\end{tabular} & & & $\mathrm{x}$ & & & 1 \\
\hline Fornencedores & & & $x$ & & & 1 \\
\hline Gestão de Infraestrutura & & & & & & 0 \\
\hline Gestão Financeira & & & & & & 0 \\
\hline Governança das transações & & & & $\mathrm{x}$ & & 1 \\
\hline Inovação de Produto & & & & & & 0 \\
\hline Investidores & & & & & & 0 \\
\hline Lucro Potencial & & & & & $\mathrm{x}$ & 1 \\
\hline Natureza dos Inputs & & & & & & 0 \\
\hline Network & & & & & & 0 \\
\hline Oferta & & & $x$ & & & 1 \\
\hline Políticas Organizacionais & & & & & & 0 \\
\hline Processo de Transformação dos Inputs & & & & & & 0 \\
\hline Proposição de Valor & $\mathrm{x}$ & & & & $\mathrm{x}$ & 2 \\
\hline Receitas & $\mathrm{x}$ & & & & & 1 \\
\hline Recursos & $x$ & & & & & 1 \\
\hline Rede de Valor & & & & & $\mathrm{x}$ & 1 \\
\hline Relacionamento com Clientes & $x$ & & & & & 1 \\
\hline Satisfação com os Stakeholders & & & & & & 0 \\
\hline Segmento de Mercado & $\mathrm{x}$ & & & & $\mathrm{x}$ & 1 \\
\hline Total & 7 & 3 & 8 & 3 & 7 & 27 \\
\hline
\end{tabular}

Quadro 1 - Quadros conceituais de modelos de negócio e seus componentes Fonte: Adaptado OROFINO, 2011

O quadro conceitual de Pateli \& Giaglis (2003) possui um número maior de elementos alinhados às premissas, seguido pelo quadro de Osterwalder \& Pigneur (2013) e, em seguida ao quadro de Chesbrough \& Rosenbloom (2002). Juntando-se os dois primeiros quadros, verifica-se que o componente "tendência de mercado, 
regulação e tecnologia" de Pateli et. al (2003) é destacado dos outros. Agregando o quadro de Chesbrough \& Rosenbloom (2002) à junção de quadro feita anteriormente, destacam-se os componentes "Lucro", "Missão", "Tecnologia”, "Tendência" e "Legislação". Cabe ressaltar que os elementos semelhantes também foram agrupados de forma que o elemento "Receitas e Custos" receberão o elemento "Lucro". Considerando o modelo de Plé, Lecocq \& Angot (2010), ressalta-se a importância das perspectivas do cliente sobre o produto ou serviço a ser oferecido, representado pelo componente "Insights do Cliente". Por último, considerando o modelo de Amit \& Zott (2001) ressalta-se os elementos "Proposição de Valor Complementar" e "Lock-in".

Analisando as similaridades e complementaridades dos modelos identificados na literatura, buscou-se sintetizar um quadro conceitual que considerasse os elementos centrais que devem estar presentes em um projeto de negócios baseado em plataformas digitais. O quadro conceitual desenvolvido pode ser visualizado na Figura 2 a seguir e descrito logo abaixo.

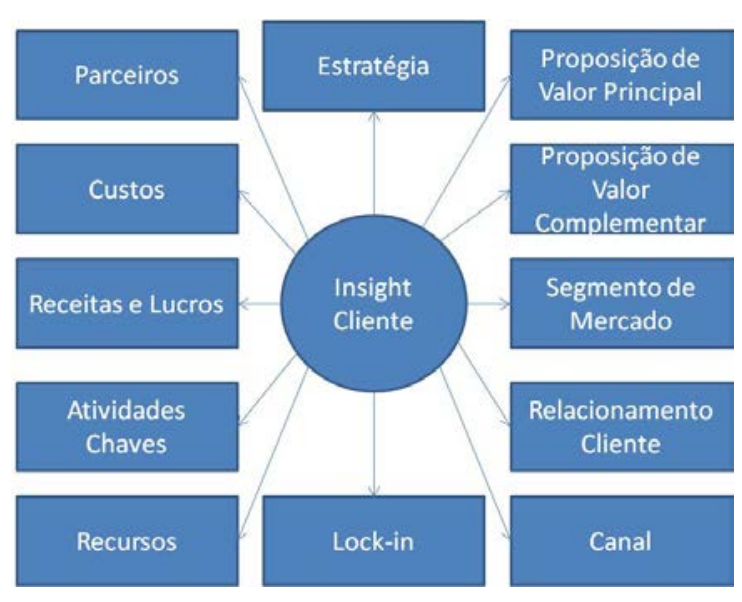

Figura 2 - Modelo sintético dos quadros conceituais de modelos digitais Fonte: Elaborado pelo autor, com base na pesquisa realizada.

- Estratégia: reconhecimento do cenário de negócio que envolve a proposição de valor. Utiliza-se as 5 forças de Porter para apoiar descrever este cenário, oferecendo informações para melhor posicionar a solução no mercado.

- Relacionamento com Cliente: funções relacionadas à captação do contato de venda com o cliente e de relacionamento com o cliente a fim de estabelecer melhores formas de oferta do produto.

- Canal: interface que a empresa encontrará e entrará em contato com cliente.

- Lock-in: geração de mecanismos e estratégias que fidelizem o cliente na utilização do produto/serviço.

- Segmento de mercado: possíveis segmentos de mercado para qual o produto/serviço será vendido.

- Proposição de valor principal: conjuntos de funcionalidades que fazem parte do produto/serviço, estruturando quais são as expectativas de resolução de problemas pela utilização do produto/serviço.

- Proposição de valor complementar: propostas de valor semelhantes que complementem uma necessidade relacionada dos clientes que se interessam pela 
proposta de valor principal. Seu objetivo é economia de tempo e custo de aquisição para adquirir outros produtos.

- Parceiros: parceiros que ajudam na produção do produto/serviço.

- Recursos: recursos necessários para a produção do produto/serviço.

- Atividades: ações que suportam a operação da produção do serviço/produto.

- Custos: custos para o desenvovimento e produção do produto/serviço.

- Receitas e lucros: fontes de receitas e tipos de precificação para a produção e venda do produto/serviço, respectivamente.

\section{MÉTODO PARA CONSTRUÇÃO DO MODELO DE NEGÓCIOS PARA A PLATAFORMA DA STARTUP}

Para contruir o modelo de negócio foram utilizadas, entrevistas com o sóciofundador e observações tiradas pelo autor deste trabalho durante as etapas de consultoria técnicas de design thinking para a construção do ambiente virtual e logomarca da plataforma ao longo deste trabalho.

Outro método utilizado foi a pesquisa em bases científica referentes ao modelo Software as a service (SaaS). Esse modelo de negócio considera os serviços disponibilizados através de servidores em nuvem para que os possíveis compradores façam a sua aquisição de acordo com suas necessidades, pagando pela quantidade ou frequência de utilização. Este modelo torna-se relevante devido a natureza do serviço prestado pela plataforma ser digital e oferecido em repositórios digitais externos à infraestrutura da empresa.

Assim, conforme as informações iam sendo coletadas, elas já eram distribuídas no quadro conceitual desenvolvido. Consta ressaltar também que aconteceram seis reuniões com o grupo NAGI (Núcleo de Apoio à Gestão da Inovação) da Uerj, composto pelo pelos autores deste artigo e alunos de iniciação científica de engenharia de produção, para a criação do modelo de negócio da startup. Essas reuniões também ofereceram informações e insights importantes para a construção do modelo de negócio da plataforma a ser desenvoldida pela empresa.

\section{A PLATAFORMA DIGITAL DA EMPRESA STARTUP}

A startup é uma organização fundada em 2013 e se encontra incubada na incubadora da Universidade do Estado do Rio de Janeiro. Essa empresa deseja criar sua própria plataforma tecnológica baseada em sistemas georreferenciados e tratamento analítico de dados. Tal plataforma abriria possibilidades de aplicações governamentais (por exemplo, no setor de Transportes, Saúde e Educação) e aplicações empresariais (por exemplo, para gestão de utilidades em fábricas). Essa plataforma deve ser capaz de apresentar indicadores de diversas naturezas através de dashboard, onde tais indicadores serão apresentados em mapas, distribuição espacial, gráficos, séries temporais e outros fatores relevantes. Esta plataforma deverá ser formada por um portal web, aplicativos para dispositivos móveis, uma API ${ }^{2}$ que poderá ser customizada e os dados na nuvem. O objetivo é que ela seja parcialmente gratuita, ou seja, os

\footnotetext{
${ }^{2}$ Uma interface entre aplicativo e programação (API) é um conjunto de instruções e padrões de programação para acesso a um aplicativo de software baseado na Web, ou ferramenta de Web. Uma empresa de software lança seu API para o público de modo a que outros criadores de software possam desenvolver produtos acionados por esse serviço. (Fonte: http://tecnologia.hsw.uol.com.br/conferencia-api1.htm)
} 
usuários poderão acessar as principais funcionalidades somente fazendo um cadastro simples, mas haverá um usuário mestre que poderá realizar tarefas na versão paga. Há possibilidade de comercialização de propagandas online.

\section{PROPOSTA DE MODELO DE NEGÓCIO PARA A PLATAFORMA DIGITAL DA STARTUP}

O conjunto de etapas previstas no método levou à construção do seguinte modelo de negócios para a plataforma da startup:

\subsection{Proposição de Valor}

- Proposição de valor principal

A plataforma da startup é um serviço online que garante a visualização de mapas dinâmicos customizados de acordo com a necessidade dos usuários. Espera-se com esta plataforma: (1) Aprimorar a tomada de decisão de gestores das mais variadas áreas; (2) Permitir um avanço no trabalho de pesquisadores com um aumento na facilidade de relacionar informações a espaços geopolíticos de forma mais precisa e customizadas; (3) Garantir acesso de uma ferramenta analítico-multidimensional ao público em geral através de um baixo custo devido a seu modelo SaaS de computação de nuvem; e, (4) Fornecer compatibilidade automatizada com outras bases de dados, assim como redes sociais.

- Proposição de valor complementar

A plataforma da startup poderá disponibilizar serviços para uso em dispositivos portáteis através de aplicativos, sendo uma forma de oferta complementar que combina as transações feitas pelos computadores pessoais e dispositivos móveis.

\subsection{Cadeia de Valor}

- Recursos chaves

Os recursos da startup são os mesmos utilizados pela empresa, como os recursos intelectuais (marca, conhecimento em geomática, Big Data e Business Intelligence) e os recursos físicos (sala, móveis, servidor, computadores, acesso rede banda larga, biblioteca de software).

- Atividades chaves

As atividades chaves consistem fundamentalmente no gerenciamento da plataforma através de ações como: (1) Analisar a demanda e propor preços especiais de aquisição para novos usuários; (2) Propor discussões nos fóruns e redes de relacionamento da plataforma; (3) Atender e responder dúvidas e problemas que surgem pelo público; e, (4) Desenvolver novas funcionalidades da plataforma.

\subsection{Atores da Cadeia}

- Segmento de mercado

No âmbito do segmento do governo, acredita-se que os detentores de poderes públicos podem utilizar a plataforma para fundamentar as tomadas de decisões relativas a qualquer questão afeta a temas como: segurança pública, saúde, educação, transportes entre outros. No âmbito corporativo a ferramenta auxilia em iniciativas de 
marketing permitindo ações de CRM mais eficazes pelos gestores e analistas de marketing. No ramo do varejo pode-se ter a antecipação das necessidades dos clientes pelos hábitos de compra em uma determinada região.

- Parceiros chaves

Os parceiros para a plataforma da startup podem ser as grandes empresas de tecnologia que oferecem soluções para startups (Microsoft, Amazon, etc), Universidades e Incubadoras de empresas (Genesis da PUC, Incubadora da COPPE, etc).

\subsection{Cenário Competitivo}

- Ameaça dos concorrentes

Atualmente muitas empresas oferecem soluções comerciais que utilizam a análise multidimensional e visualização cartográfica, contudo nem todas estas soluções podem ser classificadas como tecnologias combinadas de análise espacial e multidimensional. O mercado está dividido basicamente em três tipos de soluções: Integradas (utilizam a combinação de tecnologias espaciais e de análise multidimensional); Espaciais e de Análise Multidimensional.

- Poder dos substitutos

O produto em desenvolvimento pela empresa é muito similar a outros que oferecem ao usuário uma plataforma de análise espacial com informações físicas, demográfica e padrões culturais sobre três grandes cidades mundiais.

- Poder dos fornecedores

As principais desenvolvedoras responsáveis pela construção de softwares que auxiliam a solução do produto em desenvolvimento pela empresa são: Amazon, Microsoft, SAP, Panorama, Oracle, Integeo, InstantAltas e ESRI.

- Poder dos clientes

A empresa é uma startup possui apenas dois anos de existência que está desenvolvendo o seu primeiro produto, portanto, a sua carteira ainda está limitada a poucos clientes.

- Poder dos novos entrantes

Os novos entrantes neste tipo de negócio precisam de conhecimentos especializados em Geomática, Business Intelligence e Big Data.

\subsection{Modelo Econômico}

- Receitas e Lucros

A plataforma pode estabelecer alguns modelos de monetização dentro do modelo de negócio digital como Taxa de uso (a plataforma poderá cobrar pela quantidade de dados a serem transmitidos) e Taxa de assinatura (venda de acesso contínuo que poderá ser feito de forma mensal ou anual). Para taxa de uso, poderá ser escolhido o modelo de preço de listas que consiste em estabelecer preços fixos para 
propostas de valores individuais. Sendo assim, cada cota comprada de dados terá uma régua única de valoração. Para taxa de assinatura, a precificação fixa também poderá ser utilizada uma vez que cada plano terá um acréscimo de funcionalidades e tamanho de cotas de dados. Sendo assim um tipo de precificação fixa poderá ser dependente da característica do produto em que o preço depende do número ou da qualidade das soluções que contam em um plano específico. Em resumo, é possível aplicar os seguintes tipos de fontes de renda de acordo com o Modelo de negócio digital B2B2C (Business to Business to Commerce): (1) Assinatura; (2) Precificação baseada no consumo;(3) Precificação baseada nos atributos/funcionalidades; (4) Anunciantes.

- Estrutura de custos

A plataforma da startup tem como característica inerente a forma de um modelo de negócio digital balizado no modelo B2B2C o que sugere um Modelo SaaS de oferta de serviços. Este tipo de proposta de valor é reconhecida pelo alto grau de terceirização de infraestrutura e pela comoditização do serviço de informação. De acordo com York (2009) é importante que a estrutura de custos da plataforma seja classificada como direcionada pelo custo, o que pode ser garantido pela automação máxima e terceirizações. Dentro dos elementos dessa estrutura é possível citar os custos fixos como salários e aluguel do espaço físico. Outro elemento são os custos variáveis como energia, serviço de comunicações e despesas com materiais de administração, além dos custos de aquisição de infraestrutura externa em nuvem e outros serviços de apoio para a manutenção da plataforma disponível todos os dias.

\subsection{Relações com os Atores}

\section{- Canais}

A plataforma da startup será baseada no padrão de modelo de negócio SaaS, sendo assim o canal de comunicação do cliente com a plataforma será pela internet. Para que o usuário possa obter o acesso, será necessário que este faça um cadastro, o que garantirá um acesso personalizado pela criação de uma chave pessoal (usuário e senha). O cadastro poderá ser sincronizado com contas de redes sociais.

\section{- Relacionamento com o cliente}

Em geral, a plataforma da startup terá um contato automatizado $24 \mathrm{~h}$ por dia e sete dias por semana através de perfis pessoais online que garantem serviços personalizados disponíveis pela plataforma de acordo com a necessidade de cada cliente. Os serviços de suporte ao usuário serão realizados via internet com atendimentos pessoais que deverão ser solicitados via conta pessoal do usuário, ou por e-mail, caso o sistema não esteja disponível.

- Lock-in

Neste componente visa-se a retenção dos clientes, portanto, sugere-se que a plataforma ofereça a funcionalidade de aquisição do serviço por cartão de crédito de modo a oferecer a possibilidade de compra automática e como contrapartida oferecer descontos aos clientes, tendo assim, como vantagem, a possibilidade da compra pelo cliente ao fim do período de utilização. Ainda para facilitar a compra recorrente é interessante que a plataforma ofereça possibilidade de cadastro dos dados de compra do cliente de forma a facilitar a próxima compra sem fazer os clientes realizar seus 
cadastros com os dados de compra novamente para cada vez que forem realizar a aquisição de um determinado plano ou assinatura oferecida.

\subsection{Cocriação}

- Insight dos clientes

Neste componente do quadro conceitual deve-se estruturar qual a visão do cliente sobre muitos aspectos da plataforma. O método dos 7 insights torna-se interessante neste caso, ao considerar as experiências do cliente quanto à aquisição de planos, ou sentimento quanto à utilização da plataforma, opinião sobre o preço pago, disposição do cliente no aprendizado da utilização da plataforma e desejos sobre novas funcionalidades, que devem ser registrados e agrupados. Estas experiências podem ser adquiridas através de questionários ou até mesmo entre fóruns, chats e redes sociais que podem oferecer espaço para que os futuros usuários dialoguem e troquem informações que servirão de insights para melhorias. Com estes insights a empresa poderá coletar material que possa ser trabalhado e com auxilio de algumas ferramentas utilizadas no processo de design thinking (como etnografia, brainstorming, mapa da empatia) registrar uma espécie de jornada do cliente na aquisição e utilização da plataforma.

\section{CONSIDERAÇÕES SOBRE A PROPOSTA DE MODELO DE NEGÓCIO DA PLATAFORMA}

Sugere-se como próximo passo, detalhar as estruturas de custos e testar quais são as melhores fontes de receitas, ambos em valores, respectivamente, de modo a definir as faixas de preços. Após a conclusão desse passo, devem ser feitos testes para verificar quais os prazos ótimos para manutenção dos clientes da base gratuita que poderão utilizar a plataforma, bem como, quais serão as funcionalidades que esses clientes poderão usufruir tendo como parâmetro a taxa de conversão desses em base de cliente paga. Outro ponto importante é estudar como a plataforma poderá ser proposta para utilização do segmento de mercado referente ao governo. A startup precisa ter o entendimento da legislação de compras e licitação vigente no Brasil de modo a subsidiar uma proposta ótima de venda da plataforma para os órgãos governamentais. Ainda no aspecto legislativo, é importante que a empresa previna-se com o entendimento de outro aspectos legais antes do oferecimento para o mercado como código de defesa ao consumidor, tributação entre outros.

\section{CONCLUSÃO}

O presente trabalho teve como objetivo a construção de um novo modelo de negócio baseado em plataforma digital. A decisão de utilizar um novo quadro conceitual para plataformas digitais foi relevante, pois atendeu ao objetivo de se identificar e evidenciar novos componentes de uma maneira que o modelo mais utilizado atualmente, o Canvas, não o faz de maneira completa. Ainda sobre o novo quadro construído, pode-se dizer que os componentes "Lock-in", "Proposta de Valor Complementar" e o "Cenário Competitivo" viabilizam a construção de um modelo estratégico voltado para a fidelização do cliente na utilização da plataforma, a redução de riscos de fracassos na introdução da plataforma no mercado (principalmente pela possível reação dos concorrentes e possíveis entrantes no mercado), bem como a definição segura sobre o desenvolvimento de funcionalidades para o produto que não 
infrinjam as leis pertinentes e que sejam atraentes para as necessidades tecnológicas do mercado. Sobre os insights de interessados e do próprio sócio fundador, pode-se concluir que foi importante para a visualização do negócio tangibilizando os insights e a estratégia para introdução no mercado. Em resumo, o presente estudo apresentou grau de relevância elevado para o entendimento do negócio, bem como evolução para os insights propostos pelo sócio fundador e sugestões propostas pelo autor desse trabalho, com objetivo de se encontrar o modelo mais consistente e viável estrategicamente.

\section{REFERÊNCIAS}

ALT, Rainer \& ZIMMERMANN, Hans-Dieter. Introduction to Special Section - Business Models. Eletronic Markets: N. 1. Vol. 11. University of St. Gallen.2001.

AMIT, Raphael. ZOTT, Christoph. Creating Value Through Business Model Innovation. MIT Sloan Management Review. Estados Unidos. 2012.

AMIT, Raphael ZOTT, Christoph. Value Creation in E-Business. Strategic Management Journal. John Wiley \& Sons. 2001.

BERRY, Tim. Hurdle The Book on Business Planning. 6 ed. Califórnia: Palo Alto Software, 2006.

CHESBOROUGH, Henry \& ROSENBLOOM, Richard. The Role of the Business Model in Capturing Value from Innovation: Evidence from Xerox Corporation's Technology Spin-Off Companies. Industrial and Corporate Change. Vol 11. N 3. 1998.

DOLABELA, Fernando. $\mathbf{O}$ segredo de Luisa. Uma ideia, uma paixão e um plano de negócios: como nasce o empreendedor e se cria uma empresa. São Paulo: Cultura, 1999.

OROFINO, Maria Augusta Técnicas de Criação do Conhecimento no Desenvolvimento de Modelos de Negócio. Dissertação de Mestrado.Universidade Federal de Santa Catarina. Florianópolis. 2011.

OSTERWALDER, Alexander \& PIGNEUR, Yves. Business Model Generation Inovação em Modelo de Negócios. Rio de Janeiro. Editora Alta Books. 2013.

OSTERWALDER, Alexander. The Business Model Ontology. HEC - I'Université de Lausanne. 2004.

PATELI, Adamantia. \& GIAGLIS, George. A research framework for Analysing eBusiness Models. European Journal of Information Systems. Palgrave Macmillan. 2004

PLÉ, Loic et. al. Customer Integrated Business Model: A theoretical framework. Université de Genéve. Management. Vol 13. 2010.

RAYPORT, Jeffrey \& JAWORSKI, Bernard. E-Commerce.1 1 Edição. Editora Mc Graw Hill. 2000.

SANGUJA, Jose. A importância do plano de negócios para criação e continuidade de micro e pequenas empresas. 2014, 61 págs. TCC - UNESC.

TAVLAKI. Euripidis. \& LOUKIS, Elena. Business Model: a prerequisite for success in the network Economy. Slovenia. University of Aegan. 2005 
TEECE, David. Business Models, Business Strategy and Innovation. Longe Range Planning. Elsevier. 2010.

ZOTT, Christoph et. al. The Business Model: Theoretical Roots, Recent Developments and Future Research. IESE Business School. University Of Navarra. 2010. 